\section{Kidney \\ Blood Pressure Research}

\title{
Three Decades of Atherosclerotic Reno- vascular Disease Management - Changing Outcomes in an Observational Study
}

\author{
Diana Vassallo ${ }^{a} \quad$ Darren Green $^{a} \quad$ James Ritchie ${ }^{a} \quad$ Constantina Chrysochou ${ }^{a}$ \\ James Blunt ${ }^{\mathrm{b}}$ Philip A. Kalra
}

aDepartment of Renal Medicine, Salford Royal NHS Foundation Trust, Salford; 'bschool of Medicine, University of Manchester, Stopford Building, Oxford Road, Manchester, United Kingdom

\section{Key Words}

Atherosclerotic renovascular disease - Chronic Kidney Disease - Epidemiology • Renal revascularization $\cdot$ Vascular protective therapy

\begin{abstract}
Background/Aims: Optimized medical therapy has improved cardiovascular outcomes in the general population. To investigate whether changes in the management of atherosclerotic renovascular disease (ARVD) have had an impact on clinical outcomes. Methods: Recruitment into this single-center prospective cohort study started in 1986. Data was analyzed retrospectively. Patients were divided into four groups based on relationship of diagnosis year to landmark randomized controlled trials (RCT); group 1 - pre-large RCT data (19862000); group 2 - post-early RCT (2001-2004); group 3 - ASTRAL study recruitment era (20042009); group 4 - post-ASTRAL (2009-2014). Results: In total, 872 patients were followed for a median 54.9 months (IQR 20.2-96.2). Over successive time-periods, there was an increase in baseline utilization of renin angiotensin blockade (RAB) (group 4: $69 \%$ vs. group 1: $31 \%$, $\mathrm{p}<0.001)$, statins $(74 \%$ vs $20 \%, p<0.001)$ and beta-blockers $(43 \%$ vs $30 \%, p=0.024)$. Median time to death, end-stage kidney disease and cardiovascular events improved except in group 4, which displayed more baseline cardiovascular comorbidities. The number of investigative angiograms performed decreased from 139 per year between 2006 and 2008 to 74 per year in group 4. Conclusions: Although fewer patients are being investigated for ARVD in our center, these have more cardiovascular comorbidities. Nonetheless, optimized medical therapy may have contributed towards improved proteinuria, renal function and clinical outcomes in patients diagnosed with ARVD.
\end{abstract}




\section{Kidney Blood Pressure Research}

Kidney Blood Press Res 2016;41:325-334

DOI: $10.1159 / 000443434$

Published online: May 26, 2016

(C) 2016 The Author(s). Published by S. Karger AG, Base www.karger.com/kbr

\section{Introduction}

Atherosclerotic renovascular disease (ARVD) frequently co-exists with cardiovascular disease in patients with systemic atherosclerosis $[1,2]$. Increased awareness of cardiovascular risk factors and progress in therapeutic options for both primary and secondary prevention of cardiovascular disease have reduced the number of cardiovascular deaths per year in the general population by $16.7 \%$ over a ten-year period between 2000 and 2010 [3]. Despite the lack of conclusive evidence as to what constitutes optimal medical therapy for patients with ARVD, observational studies have shown that the use of renin-angiotensin blockade (RAB) and statin therapy, as specified in the CORAL protocol [4], may improve clinical outcomes in patients with ARVD [5-7]. However, it is not clear whether these changes in clinical practice have translated into improvement in clinical cardiovascular outcomes specifically in ARVD as is the case in other cardiovascular disease settings.

There is also evidence that fewer patients with ARVD are progressing to end-stage kidney disease (ESKD); while more than three decades ago up to $41 \%$ of patients with ARVD suffered significant renal 'failure events' $(\geq 10 \%$ decrease in renal length, $\geq 100 \%$ increase in serum creatinine or $\geq 50 \%$ decrease in creatinine clearance) during up to 4 years followup [8], the latest trials report that half as many patients (16-22\%) reached adverse renal end-points (acute kidney injury or renal death in ASTRAL; doubling of serum creatinine in CORAL) over a similar follow-up period [9].

A further reason why ARVD outcomes may have improved independent of better therapeutic options in cardiovascular disease is earlier diagnosis due to more widespread use of non-invasive imaging techniques $[10,11]$.

The aim of this study is twofold; first, we aim to illustrate how clinical phenotype and management of ARVD have evolved over the past three decades and second, we aim to investigate whether changes in clinical management of ARVD correlate with improved clinical outcomes, utilizing the resource of a single renal center database in which the phenotype of ARVD patients has been recorded in detail.

\section{Materials and Methods}

This study involved retrospective analysis of an observational study first started in 1986. Information on all patients with ARVD referred to or diagnosed at our tertiary renal center (catchment population of 1.55 million) since this time was entered into a local renovascular database. Ethical approval was granted from the local ethics committee. Data were collected on each patient annually, using hospital patient records. Data collected include presenting features of ARVD, baseline demographics (age at diagnosis, gender), co-morbid conditions (diabetes, macrovascular disease), renal imaging results including angiography, annualized prescribed medications, blood pressure, serum creatinine (umol/L) and proteinuria (g/24h), together with clinical outcome data. The degree of renal artery stenosis (RAS) was obtained from biplane angiography (intravenous digital subtraction angiography (IVDSA) or intra-arterial digital subtraction angiography (IADSA) in earlier studies, computed tomographic (CT) or magnetic resonanace (MR) angiography) and reported by two specialist radiologists over the 30 year period. The reported severity of the RAS was then recorded in the database in a standardized manner using a 'patency score'; a score of 200 was equivalent to $0 \%$ bilateral stenosis while a score of 0 meant $100 \%$ bilateral occlusion. Flash pulmonary oedema (FPE) was defined as acute decompensated heart failure in the absence of a documented precipitating cardiac event or known reduced left ventricular ejection fraction $(<40 \%)$. Estimated glomerular filtration rate (eGFR) was calculated using the CKD Epidemiology Collaboration equation (CKD-EPI). Patients with incomplete baseline information were excluded from this analysis. The date of diagnostic imaging was considered as time zero. New patients were entered into the database up until $31^{\text {st }}$ August 2014 and data was censored at the earliest of death or $11^{\text {th }}$ May 2015 if still known to our services or last patient encounter if discharged or lost to follow-up.

All patients were managed in accordance with the contemporary vascular protective advice and UK Renal Association blood pressure targets $[12,13]$ at time of entry into the database. Renal revascularization was performed either in accordance with physician preference or after entry into a randomized trial [4, 


\section{Kidney Blood Pressure Research}

Kidney Blood Press Res 2016;41:325-334

DOI: 10.1159/000443434

Published online: May 26, 2016

(C) 2016 The Author(s). Published by S. Karger AG, Base

www.karger.com/kbr

Management

14]. All revascularization procedures involved percutaneous transluminal angioplasty, with deployment of bare-metal stents since 1998; no embolic protection devices were used.

Predefined primary clinical end-points included:

(1) Date of death

(2) Date of first cardiovascular event after enrollment, a composite of acute coronary syndrome or myocardial infarction, new arrhythmias, pulmonary oedema or decompensated heart failure, cerebrovascular events including transient ischaemic attacks, peripheral vascular disease including peripheral revascularization and abdominal aortic aneurysm repair, and mesenteric ischaemia.

(3) Date of reaching ESKD defined as the earliest of the following events: initiation of renal replacement therapy [RRT] [including renal transplantation] or reaching eGFR $<10 \mathrm{ml} / \mathrm{min} / 1.73 \mathrm{~m}^{2}$ which is the average eGFR at which RRT is started in the UK [15]

(4) A composite end-point composed of the first of any of the above events.

A secondary clinical end-point was rate of change of eGFR from time zero to end of study calculated from slope of linear regression, excluding blood results taken during in-patient stay, patients who presented requiring RRT, or those who had less than one year follow-up or less than 3 data points.

\section{Statistical Analysis}

Patients were divided into four groups based on the relationship of their diagnosis year to that of publication of landmark studies related to management of ARVD: 1986-2000 (Group 1; early studies up until publication of three small RCTs [16-18]), 2001-2004 (Group 2; studies advocating benefits of medical therapy [5, 19]), 2005-2008 (Group 3; main ASTRAL recruitment period[14]) and 2009-2014 (Group 4; post-ASTRAL era [4, 14]). Baseline characteristics were compared across these four groups; categorical data were compared using Chi-squared tests while Kruskal-Wallis was used to compare continuous variables, as these were all non-parametrically distributed on the Shapiro-Wilk test. These non-parametric continuous variables were described using median (interquartile range). Pairwise analyses were performed using post-hoc tests for Kruskal-Wallis and Chi-squared test [20]. Kaplan-Meier curves were constructed for outcomes in each group and used to estimate the median times to event for each outcome. Incidence rates per 100 patient years were calculated manually for each group. A Cox proportional hazards regression model was used to evaluate the effect of successive time periods on the primary end-point; this was adjusted for baseline age, gender, blood pressure, eGFR and proteinuria.

\section{Results}

A total of 894 patient records were reviewed; 22 patients were excluded due to incomplete baseline data (missing date of imaging study, imaging results, comorbidities or baseline medications). Data from 872 patients were analysed, with a median follow-up of 54.9 months (IQR 20.2-96.2). There were 265 patients in Group 1, 235 patients in Group 2, 287 patients in Group 3 and 85 patients in Group 4 (Table 1).

There was a predominance of male patients in all four groups and the median age of patients diagnosed with ARVD increased significantly after 2000 ( 72.9 years after 2000 compared to 68.3 years for Group 1, p<0.0005), although this was lower in Group 4 (Group 1 vs Group 4, $\mathrm{p}=$ non-significant). Results showed a rise in prevalence of diabetes in patients recruited after 2000 (from 21.5\% for Group 1 to 38.3\% for Group 2, p<0.0005). A higher proportion of patients recruited after 2009 had a greater burden of symptomatic coronary artery disease (68.2\% in Group 4 vs $47.7 \%$ in Group 3, p =0.001), congestive heart failure (26.5\% in Group 4 vs $12.0 \%$ in Group 3, p=0.001) and flash pulmonary oedema $(11.8 \%$ in Group 4 vs 4.9\% in Group 3, $\mathrm{p}=0.023$ ) when compared to earlier groups.

Blood pressure control at time of diagnosis improved after 2000, although average blood pressure readings for Group 4 were more elevated than for preceding years. The decrease in average blood pressure after 2000 occurred in parallel with an increase in the number of antihypertensive agents used; a greater proportion of patients diagnosed after 2000 were prescribed $>3$ anti-hypertensive agents (31\% in Group 1 compared to $49 \%$ in Group 2, p<0.0005), 


\section{Kidney \\ Blood Pressure Research}

Kidney Blood Press Res 2016;41:325-334

\begin{tabular}{l|l}
\hline DOI: 10.1159/000443434 & (c) 2016 The Author(s). Published by S. Karger AG, Basel \\
\hline
\end{tabular}

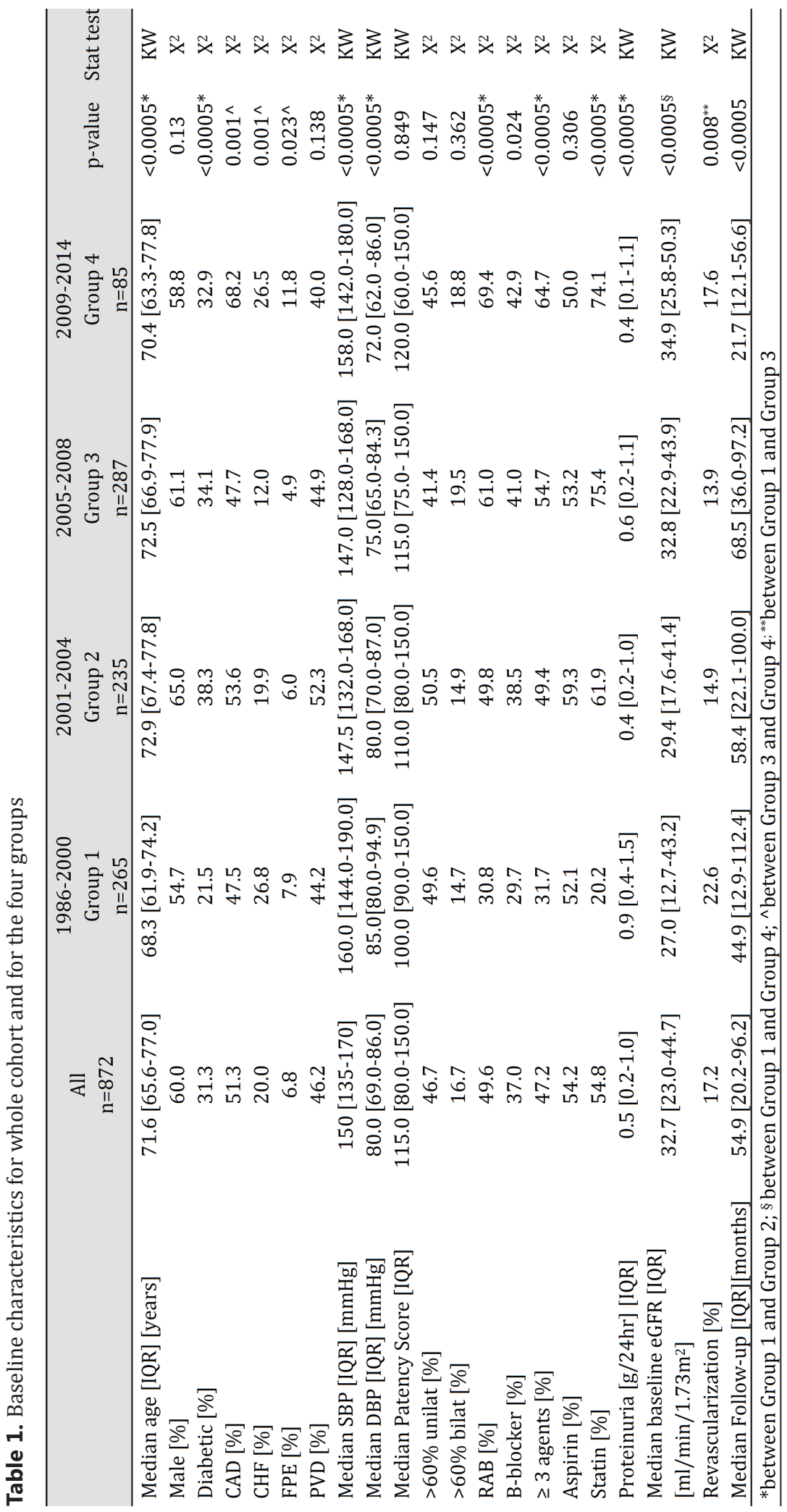

a finding which persisted throughout all groups.

The most important change in prescribing practice was the sharp increase in the proportion of patients treated with RAB $\quad 30.8 \%$ in Group 1 compared to $69.4 \%$ Group 4 , p<0.0005), beta-blockers $(29.7 \%$ in Group 1 compared to $42.9 \%$ in Group 4, p=0.024) and statins $(20.2 \%$ in Group 1 compared to $74.1 \%$ in Group 4, p<0.0005) at time of diagnosis over successive time periods (figure 1). Following the year 2000 there was an increase in the proportion of ARVD patients without confirmed macrovascular disease (MVD) established on at least one vascular protective agent (RAB, statin, beta-blocker or Aspirin) at baseline (table 2), although overall, less patients without documented MVD were on vascular protective therapy at time of diagnosis of ARVD than those known to have MVD .

There was a parallel significant decline in baseline proteinuria between Group 1 and Group 2 (from $0.9 \mathrm{~g} /$ day to $0.4 \mathrm{~g} / \mathrm{day}, \mathrm{p}<0.0005$ ), which then plateaued in the subsequent time periods, and this was in keeping with the fact that baseline renal 


\section{Kidney Blood Pressure Research}

function (eGFR) was progressively better with each subsequent cohort $\quad(p<0.0005$ between Group 1 and Group 4). However, overall there was no significant change in the rate of eGFR decline over followup time $(0.98 \mathrm{ml} /$ min $/ 1.73 \mathrm{~m}^{2} /$ year across all four groups, table 3). Patients in the latest cohort were noted to have a slightly higher patency score, although this was not statistically significant.

Survival curves revealed an improvement in the median time to clinical endpoints over successive time periods, with the exception of Group 4, which was characterized by a higher burden of coronary artery disease and heart failure at baseline (table 4; figure 2). An analysis of the incidence of combined primary end-points per 100 patient years revealed that Group 3 had the lowest incidence of adverse events compared to the other groups (26.32 for Group 1; 28.34 for Group 2; 20.11 for Group 3 and 23.67 for Group 4). This was also shown in the Cox regression model where Group 1 was used as a referrant group. Hazard ratios for Group 4 were non-significant (table 5).

An analysis of the annual number of patients diagnosed with ARVD and the number of revascularization procedures performed annually over the past three decades revealed a biphasic pattern; there was a decline in both the number of revascularizations performed and the number of patients diagnosed with ARVD in 2001-2004 and 2009-2014 (figure 3). Data on the total number of CTAs and MRAs performed to investigate the presence of ARVD was only available from 2006 onwards; there was a corresponding decline in the total number of CTAs and MRAs performed in the latest cohort. For example, 277 investigations were performed over a two-year period between 2006 and 2008, while 297 investigations were performed over 4 years between 2009 and 2014. An analysis of the rate of revascularization procedures revealed an increase from the earliest to middle two cohorts, with annual figures of 4 in cohort 1, 9 and 10 in cohorts 2 and 3, respectively, falling to 3 procedures per year in

Table 2. Percentage of ARVD patients with and without documented macrovascular disease (MVD) on vascular protective therapy

\begin{tabular}{lcc}
\hline & $\begin{array}{c}\text { Percentage of ARVD patients } \\
\text { without confirmed MVD on } \\
\text { vascular protective therapy* } \\
\text { at baseline }\end{array}$ & $\begin{array}{c}\text { Percentage of ARVD patients with } \\
\text { confirmed MVD on vascular } \\
\text { protective therapy* at baseline }\end{array}$ \\
\hline Group 1 & 65.91 & 83.62 \\
Group 2 & 80.70 & 90.45 \\
Group 3 & 90.00 & 93.91 \\
Group 4 & 82.35 & 97.06 \\
\hline * any of aspirin, statin, renin-angiotensin blockade or beta-blocker
\end{tabular}

Fig. 1. Proportion of patients in each group receiving specific vascular protective agents (renin angiotensin blockage, beta-blockers, statins or aspirin) at time of diagnosis. 


\section{Kidney \\ Bloód Pressure Research}

\begin{tabular}{|c|c|}
\hline Kidney Blood Press Res 2 & $1: 325-334$ \\
\hline DOI: 10.1159/000443434 & (C) 2016 The Author(s). Published by S. Karger AG, Basel \\
\hline
\end{tabular}

Published online: May 26, 2016 www.karger.com/kbr

Vassallo/Green/Ritchie/Chrysochou/Blunt/Kalra: Three Decades of Atherosclerotic Disease Management

Table 3. Rate of eGFR decline calculated from slope of linear regression for the whole cohort and the individual groups

\begin{tabular}{lccccccc}
\hline & $\begin{array}{c}\text { All } \\
\mathrm{n}=872\end{array}$ & $\begin{array}{c}1986-2000 \\
\mathrm{n}=265\end{array}$ & $\begin{array}{c}2001-2004 \\
\mathrm{n}=235\end{array}$ & $\begin{array}{c}2005-2008 \\
\mathrm{n}=287\end{array}$ & $\begin{array}{c}2009-2014 \\
\mathrm{n}=85\end{array}$ & $\begin{array}{c}\mathrm{p}- \\
\text { value }\end{array}$ & $\begin{array}{r}\text { Stat } \\
\text { test }\end{array}$ \\
\hline $\begin{array}{l}\text { Median eGFR slope } \\
\text { [ml/min/1.73m²/year }]\end{array}$ & -0.98 & -1.52 & -1.00 & -0.71 & -1.09 & & \\
(across all four groups) & {$[-2.60-0.52]$} & {$[-3.45--0.03]$} & {$[-244-0.72]$} & {$[-2.23-0.52]$} & {$[-3.60-2.20]$} & $0.181^{*}$ & KW \\
\hline
\end{tabular}

Table 4. Median time to end-points for each group and for cohort as a whole (in months)obtained from non-adjusted Kaplan-Meier curves

\begin{tabular}{lcccc}
\hline & Death & CVE* & ESKD* & Any \\
\hline 1 & $45.1[35.0-55.2]$ & $40.4[32.9-48.0]$ & $35.2[26.2-44.2]$ & $34.4[26.9-41.9]$ \\
2 & $58.9[49.9-68.0]$ & $42.8[34.6-51.1]$ & $49.7[41.7-57.8]$ & $36.8[28.6-44.9]$ \\
3 & $81.6[68.8-94.5]$ & $47.5[40.8-78.3]$ & $70.2[57.9-82.4]$ & $42.4[36.1-48.7]$ \\
4 & $65.4[53.4-77.3]$ & $59.5[40.8-78.3]$ & $60.8[43.2-78.4]$ & $55.9[37.7-74.1]$ \\
All & $63.0[57.0-69.1]$ & $43.8[39.8-47.8]$ & $54.9[49.0-60.7]$ & $39.5[35.2-43.7]$ \\
\hline
\end{tabular}
* Adjusted for death

(a)

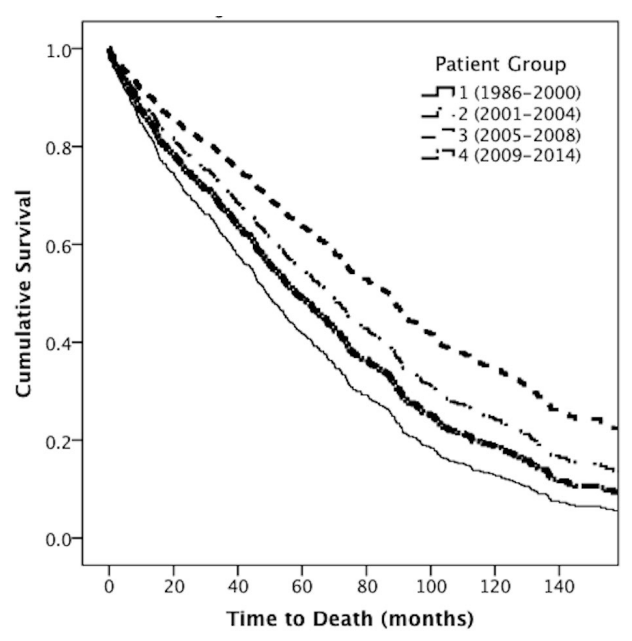

(c)

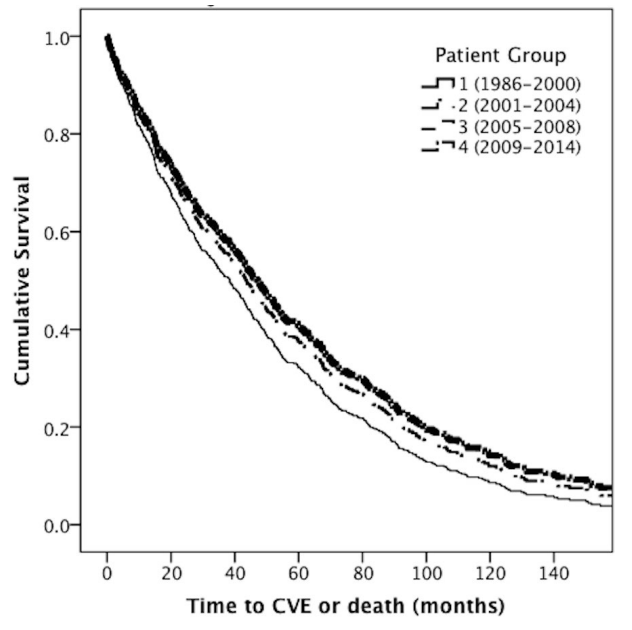

(b)

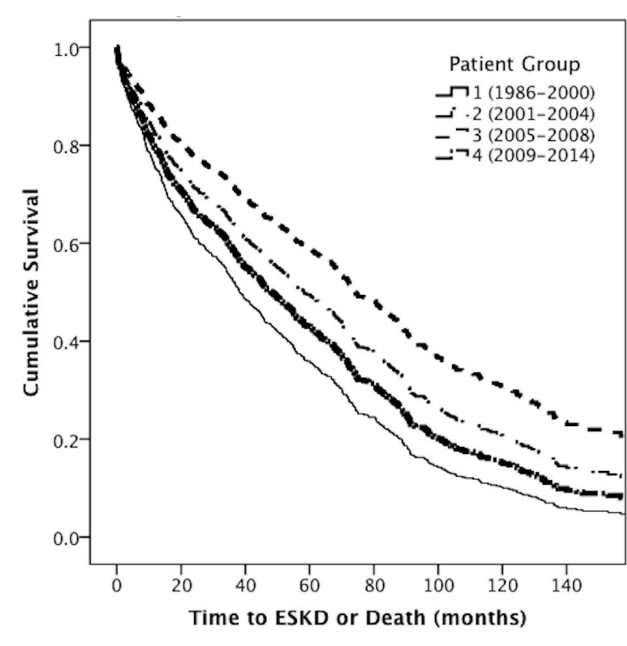

(d)

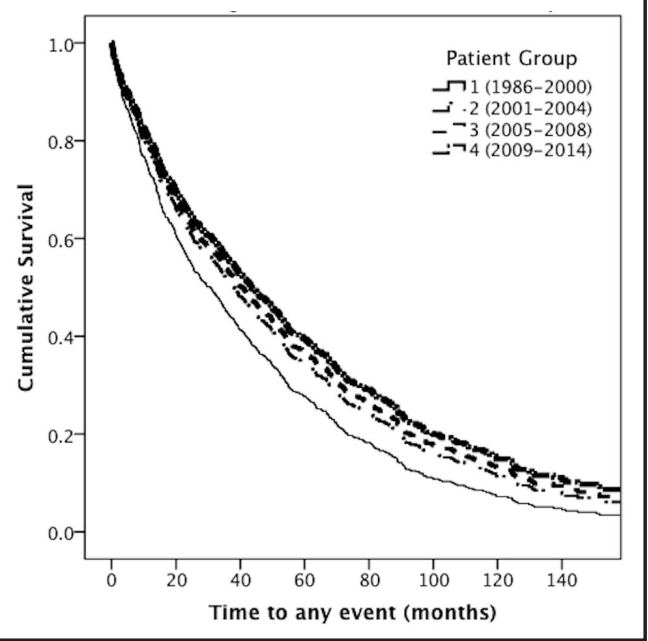

Fig. 2. (a-d) Kaplan-Meier curves for time to (a) Death, (b) ESKD, (c) CVE and (d) any event for each group (adjusted for age, gender, macrovascular disease, flash pulmonary oedema, diabetes and baseline eGFR and proteinuria).

the post-ASTRAL cohort. However, the proportion of registered ARVD patients who underwent revascularization was greatest in the latest cohort (Group 1, 3.88 revascularizations per 100 patient years, Group 4, 6.46 revascularizations per 100 patient years). 


\section{Kidney \\ Blood Pressure Research}

Table 5. Hazard ratio for endpoints in each time period compared to 1986-2000 (reference group), adjusted for age, gender, blood pressure, comorbidities (Macrovascular disease, diabetes, congestive heart failure and flash pulmonary oedema) eGFR and degree of proteinuria at baseline.

\begin{tabular}{lcccccccccccc}
\hline Group & \multicolumn{4}{c}{ Death } & \multicolumn{4}{c}{ CVE $^{*}$} & \multicolumn{3}{c}{ ESKD* } & \multicolumn{4}{c}{ Any } \\
\cline { 2 - 13 } & HR & $95 \%$ CI & P value & HR & $95 \%$ CI & P value & HR & $95 \%$ CI & P value & HR & $95 \%$ CI & P value \\
\hline 2 & 0.71 & $0.0 .57-0.89$ & 0.003 & 1.30 & $0.94-1.79$ & 0.116 & 0.81 & $0.537-1.23$ & 0.327 & 0.86 & $0.7-1.08$ & 0.24 \\
3 & 0.54 & $0.42-0.69$ & $<0.0005$ & 1.35 & $0.97-1.87$ & 0.079 & 0.49 & $0.30-0.80$ & 0.004 & 0.84 & $0.67-1.05$ & 0.127 \\
4 & 0.84 & $0.54-1.3$ & 0.432 & 0.872 & $0.47-1.62$ & 0.665 & 0.76 & $0.32-1.80$ & 0.534 & 0.76 & $0.50-1.16$ & 0.209 \\
\hline
\end{tabular}

Fig. 3. Number of patients diagnosed with ARVD and number of revascularization procedures performed each year in relation to important events and turning points in the history of management of ARVD.

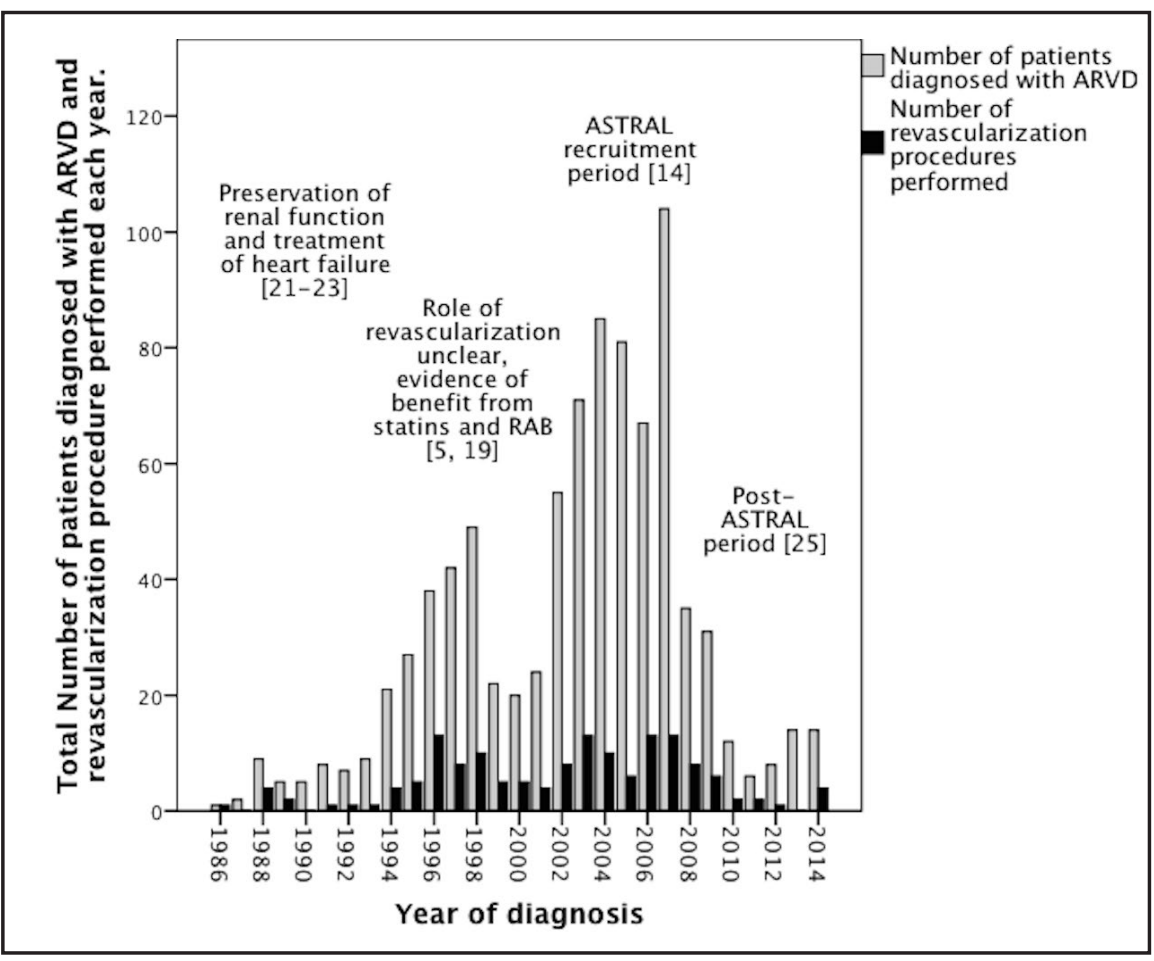

\section{Discussion}

To our knowledge, this database is the largest observational study of ARVD given its size, length of follow-up and comprehensive data collection. These results provide unique insight into how treatment practices and outcomes of this condition have evolved over the years.

Our study suggests that enthusiasm for diagnosing and treating ARVD has been clearly influenced by publication of major studies performed in this field. Despite early enthusiasm for revascularization both for preservation of renal function and treatment of flash pulmonary oedema [21-23], concerns regarding the potential hazards of this intervention and the absence of benefit over medical treatment in unselected populations, as shown in both the small early studies $[16,18]$ and the more recent and far larger ASTRAL and CORAL studies, have led to a decline in revascularization rates $[4,14]$. There was a corresponding sharp decrease in the number of patients diagnosed with ARVD in the post-ASTRAL period and we feel that this was because fewer angiographic investigations were being performed, as these declined from around 139 CTA/MRA investigations per year almost a decade ago to around 74 investigations per year in our center in the post-ASTRAL cohort. These figures may reflect both a reduced interest in actively investigating for ARVD, and also that during the 'ASTRAL recruitment period' there was heightened interest in investigating for underlying ARVD. 


\section{Kidney Blood Pressure Research}

Kidney Blood Press Res 2016;41:325-334

DOI: 10.1159/000443434

Published online: May 26, 2016

(C) 2016 The Author(s). Published by S. Karger AG, Basel www.karger.com/kbr

Patients in Group 4 were fewer in number and older with a higher burden of comorbidities compared to earlier groups. This suggests that in the present era, more patients with certain high-risk features are being referred for radiological investigations; such patients were underrepresented in ASTRAL and CORAL. Indeed, although less revascularization procedures have been performed per year in the post-ASTRAL period compared to earlier years, the percentage of newly diagnosed ARVD patients who undergo revascularization is significantly higher in this last cohort, reflecting a selected population. Forgoing investigations for ARVD may be the correct option in the large majority of patients in whom revascularization will not lead to benefit, either due to functionally insignificant RAS [24] or irreversible renal parenchymal injury [25]. However, there is a concern that reduced enthusiasm for investigation may lead to missed opportunities for timely diagnosis of ARVD [9]. There is evidence that this intervention may improve clinical outcomes in patients with clinical features suggestive of critical RAS and viable renal parenchyma. A recent observational study from our group analyzed clinical outcomes for 237 patients with at least 50\% RAS and one or more 'high-risk' features (uncontrolled hypertension, rapidly deteriorating renal function or flash pulmonary oedema); around a quarter of these patients underwent revascularization either as part of a research study (ASTRAL or CORAL) or if thought to be clinically indicated, while the rest were treated medically as per contemporary guidelines. Revascularization led to improved clinical outcomes in patients with either flash pulmonary oedema or in those with combined rapidly declining renal function and uncontrolled hypertension hence this intervention may benefit carefully selected patients [26].

Our results highlight how increased emphasis on cardiovascular risk reduction in patients with systemic atherosclerosis has driven increased utilization of statins, RAB, and beta-blockers in patients with ARVD, although there is still room for improvement especially when compared to patients with established cardiovascular disease. This change in prescribing practice appeared to be associated with improved blood pressure control, lower proteinuria and a higher baseline eGFR over the years; these are all well-established independent predictors of better renal and patient survival $[27,28]$. It is however difficult to interpret causal associations from such a retrospective study. Although group 4 was noted to have a similar incidence of end-points and rate of decline of eGFR to Group 1 despite a worse cardiovascular risk profile at diagnosis, the better baseline eGFR and proteinuria in recent years could well be the result of earlier diagnosis of ARVD due to more widespread use of non-invasive angiographic investigations. Any detectable long-term benefit of intensified vascular protective therapy could have been offset by selection bias, as the post-ASTRAL period was characterized by patients with a higher comorbid burden. Conversely, the apparent improved outcomes that characterized group 3 could reflect the fact that this period coincided with the major phase of ASTRAL recruitment; indeed, our renal department was a major recruitment center for ASTRAL and 74 patients were recruited between 2002 and 2008. Recruitment of lower risk patients may have confounded our results, and this was an effect seen in ASTRAL. However a separate analysis comparing baseline characteristics of all Group 3 patients against Group 3 patients excluding those recruited into ASTRAL, revealed no significant difference between the two groups.

This large observational single-center study has several limitations due to its retrospective nature. Data collection was performed in a standardized manner but by different individuals over almost three decades thus possibly introducing assignment bias. As described above, selection bias in diagnosing ARVD has clearly influenced results, with an over-representation of low-risk patients in Group 3 and evidence that Group 4 includes patients with greater co-morbidity burden. Although adjusted for baseline comorbidities, renal function and proteinuria, the Cox model was not adjusted for medications. This is because longitudinal data on the administration of cardioprotective medication was not available and for the purpose of this analysis it was assumed that these were continued for the duration of the follow-up period. In addition, a number of important variables, which would have been relevant to clinical outcomes, were not included due to missing or unreliable data. Amongst these are BMI, smoking status and drug dosage. Cause of death was also not available, al- 


\section{Kidney \\ Blood Pressure Research}

Kidney Blood Press Res 2016;41:325-334

DOI: $10.1159 / 000443434$

Published online: May 26, 2016

(C) 2016 The Author(s). Published by S. Karger AG, Basel

www.karger.com/kbr

Vassallo/Green/Ritchie/Chrysochou/Blunt/Kalra: Three Decades of Atherosclerotic Disease Management

though we would assume that there was a predominance of cardiovascular deaths in this ARVD population in keeping with evidence from the literature [29]. Blood pressure was documented from the single office reading taken at time of diagnosis. The degree of stenosis was determined by a single radiologist viewing each scan, based on biplanar imaging studies (CTA or MRA), without confirmation of haemodynamic significance of the stenosis. Lastly, the last cohort depicting the post-ASTRAL era was smaller in size and had a significantly shorter follow-up time compared to the other cohorts, potentially confounding results.

\section{Conclusion}

This study illustrates how management of ARVD has evolved over the years. Our results suggest that the advent of enhanced vascular protective therapy after 2000 may have contributed towards improved baseline proteinuria and eGFR in newly diagnosed ARVD patients however selection bias has affected interpretation of our results. In the wake of neutral results of the ASTRAL and CORAL trials, fewer patients, but a greater proportion with more cardiovascular comorbidities are being referred for investigation of ARVD, and this is likely to explain the apparent worse outcomes in the latest cohort. Timely revascularization may be beneficial in selected individuals hence it is imperative that renal physicians maintain a high index of clinical suspicion for ARVD. Further studies are required to help define this important sub-group and target revascularization more appropriately.

\section{Disclosure Statement}

None declared.

\section{References}

1 Park S, Jung JH, Seo HS, Ko YG, Choi D, Jang Y, Chung N, Cho SY, Shim WH: The prevalence and clinical predictors of atherosclerotic renal artery stenosis in patients undergoing coronary angiography. Heart Vessels 2004;19:275-279.

2 Harding MB, Smith LR, Himmelstein SI, Harrison K, Phillips HR, Schwab SJ, Hermiller JB, Davidson CJ, Bashore TM: Renal Artery Stenosis: prevalence and associated risk factors in patients undergoing routine cardiac catheterization. J Am Soc Nephrol 1992;2:1608-1616.

3 Go AS, Mozaffarian D, Roger VL, Benjamin EJ, Berry JD, Blaha MJ, Dai S, Ford ES, Fox CS, Franco S, Fullerton HJ, Gillespie C, Hailpern SM, Heit JA, Howard VJ, Huffman MD, Judd SE, Kissela BM, Kittner SJ, Lackland DT, Lichtman JH, Lisabeth LD, Mackey RH, Magid DJ, Marcus GM, Marelli A, Matchar DB, McGuire DK, Mohler ER 3rd, Moy CS, Mussolino ME, Neumar RW, Nichol G, Pandey DK, Paynter NP, Reeves MJ, Sorlie PD, Stein J, Towfighi A, Turan TN, Virani SS, Wong ND, Woo D, Turner MB; American Heart Association Statistics Committee and Stroke Statistics Subcommittee: Executive Summary: Heart Disease and Stroke Statistics 2014 Update: A Report From the American Heart Association. Circulation 2014;129:399-410.

4 Cooper CJ, Murphy TP, Cutlip DE, Jamerson K, Henrich W, Reid DM, Cohen DJ, Matsumoto AH, Steffes M, Jaff MR, Prince MR, Lewis EF, Tuttle KR, Shapiro JI, Rundback JH, Massaro JM, D'Agostino RB Sr, Dworkin LD; CORAL Investigators: Stenting and medical therapy for atherosclerotic renal-artery stenosis. N Engl J Med 2014;370:13-22.

5 Losito A, Errico R, Santirosi P, Lupattelli T, Scalera GB, Lupattelli L: Long-term follow-up of atherosclerotic renovascular disease. Beneficial effect of ACE inhibition. Nephrol Dial Transplant 2005;20:1604-1609.

6 Tonelli M: The effect of statins on preservation of kidney function in patients with coronary artery disease. Curr Opin Cardiol 2006;21:608-612.

7 Chrysochou C, Foley RN, Young JF, Khavandi K, Cheung CM, Kalra PA: Dispelling the myth: the use of reninangiotensin blockade in atheromatous renovascular disease. Nephrol Dial Transplant 2012;27:1403-1409. 


\section{Kidney \\ Blood Pressure Research}

Kidney Blood Press Res 2016;41:325-334

DOI: $10.1159 / 000443434$

Published online: May 26, 2016

(C) 2016 The Author(s). Published by S. Karger AG, Basel www.karger.com/kbr

8 Dean R, Kieffer R, Smith B, Oates JA, Nadeau JH, Hollifield JW, DuPont WD: Renovascular hypertension: Anatomic and Renal function changes during drug therapy. Arch Surg 1981;116:1408-1415.

9 Herrmann SMS, Saad A, Textor SC: Management of atherosclerotic renovascular disease after Cardiovascular Outcomes in Renal Atherosclerotic Lesions (CORAL). Nephrol Dial Transplant 2014;30:366375.

10 Kalra PA, Guo H, Gilbertson DT, Liu J, Chen SC, Ishani A, Collins AJ, Foley RN: Atherosclerotic renovascular disease in the United States. Kidney Int 2010;77:37-43.

11 Yu MS, Folt DA, Drummond CA, Haller ST, Cooper EL, Brewster P, Evans KL, Cooper CJ: Endovascular versus medical therapy for atherosclerotic renovascular disease. Curr Atheroscler Rep 2014;16:459.

12 Goddard J, Harris K, Turner N: The UK eCKD guide, 2009. http://www.renal.org/ckd. Accessed October 26, 2015.

13 National Institute for Health and Care Excellence. Hypertension in adults: diagnosis and management. NICE guidelines, 2011. http://www.nice.org.uk/guidance/cg127. Accessed October 26, 2015.

14 ASTRAL Investigators, Wheatley K, Ives N, Gray R, Kalra PA, Moss JG, Baigent C, Carr S, Chalmers N, Eadington D, Hamilton G, Lipkin G, Nicholson A, Scoble J: Revascularization versus medical therapy for renal-artery stenosis. N Engl J Med 2009;361:1953-1962.

15 Gilg J, Rao A, Fogarty D: UK Renal Registry 15th annual report: Chapter 1 UK RRT incidence in 2011: national and centre-specific analyses. Nephron Clin Pract 2013;123:S1-28.

16 Plouin P-F, Chatellier G, Darné B, Raynaud A, Study G for the EMM vs A (EMMA): Blood Pressure Outcome of Angioplasty in Atherosclerotic Renal Artery Stenosis: A Randomized Trial. Hypertension 1998;31:823-829.

17 Webster J, Marshall F, Abdalla M, Dominiczak A, Edwards R, Isles CG, Loose H, Main J, Padfield P, Russell IT, Walker B, Watson M, Wilkinson R: Randomised comparison of percutaneous angioplasty vs continued medical therapy for hypertensive patients with atheromatous renal artery stenosis. J Hum Hypertens 1998;12:329-335.

18 Van Jaarsveld BC, Krijnen P, Pieterman H, Derkx FH, Deinum J, Postma CT, Dees A, Woittiez AJ, Bartelink AK, Man in 't Veld AJ, Schalekamp MA: The effect of balloon angioplasty on hypertension. N Engl J Med 2000;342:1007-1014.

19 Chabova V, Schirger A, Stanson A, McKusick M, Textor S: Outcomes of Atherosclerotic renal artery stenosis managed without revascularisation. Mayo Clin Proc 2000;75:437-444.

20 Beasley T, Schumacker R: Multiple regression approach to analyzing contingency tables: Post hoc and planned comparison procedures. J Exp Educ 1995;64:79-93.

21 Pickering TG, Herman L, Devereux RB, Sotelo JE, James GD, Sos TA, Silane MF, Laragh JH: Recurrent pulmonary oedema in hypertension due to bilateral renal artery stenosis: treatment by angioplasty or surgical revascularisation. Lancet 1988;2:551-552.

22 Harden PN, MacLeod MJ, Rodger RSC, Baxter GM, Connell JM, Dominiczak AF, Junor BJ, Briggs JD, Moss JG: Effect of renal-artery stenting on progression of renovascular renal failure. Lancet 1997;349:1133-1136.

23 MacDowall P, Kalra P, O’Donoghue D, Waldek S, Mamtora H, Brown K: Risk of morbidity from renovascular disease in elderly patients with congestive cardiac failure. Lancet 1998;352:13-16.

24 Drieghe B, Madaric J, Sarno G, Manoharan G, Bartunek J, Heyndrickx GR, Pijls NH, De Bruyne B: Assessment of renal artery stenosis: side-by-side comparison of angiography and duplex ultrasound with pressure gradient measurements. Eur Heart J 2008;29:517-524.

25 Textor SC, Lerman LO: Paradigm Shifts in Atherosclerotic Renovascular Disease: Where Are We Now? J Am Soc Nephrol 2015;26:2074-2080.

26 Ritchie J, Green D, Chrysochou C, Chalmers N, Foley RN, Kalra PA: High-risk clinical presentations in atherosclerotic renovascular disease: prognosis and response to renal artery revascularization. Am J Kidney Dis 2014;63:186-197.

27 Hillege HL: Urinary Albumin Excretion Predicts Cardiovascular and Noncardiovascular Mortality in General Population. Circulation 2002;106:1777-1782.

28 Go A, Chertow G, Fan D, Mcculloch CE, Hsu C: Chronic Kidney Disease and the Risks of Death, Cardiovascular Events, and Hospitalization. New Eng J Med 2004;351:1296-1305.

29 Kalra PA, Guo H, Kausz AT, Gilbertson DT, Liu J, Chen SC, Ishani A, Collins AJ, Foley RN: Atherosclerotic renovascular disease in United States patients aged 67 years or older: risk factors, revascularization, and prognosis. Kidney Int 2005;68:293-301. 